\title{
Prevalence, Resistance Profile and Virulence Genes of Streptococcus agalactiae Colonizing Near-term Pregnant Women Attending Ain Shams University Hospital
}

\author{
Noha G. Abdallah ${ }^{1 *}\left(\mathbb{D}\right.$, Faten M. Ali ${ }^{1}$ D , Lamiaa A. Adel $^{1}(\mathbb{D}$, \\ Ahmed M. Elkotb² (D) and Walaa A. Ibrahim ${ }^{1}$ (D) \\ ${ }^{1}$ Department of Medical Microbiology and Immunology, Faculty of Medicine, Ain Shams University, Abbasya, \\ Postal code - 11591, Cairo, Egypt. \\ ${ }^{2}$ Department of Obstetric and Gynecology, Faculty of Medicine, Ain Shams University, Abbasya, Postal code - \\ 11591, Cairo, Egypt.
}

\begin{abstract}
Group B streptococcus (GBS) is a common cause of infections in pregnant females and non-pregnant adults with chronic diseases (such as diabetes and cancer), also it is the main reason of septicaemia and meningitis in infants. The aim of this study was to figure out how common GBS is in pregnant women, the antimicrobial sensitivity pattern of the isolated GBS colonies and check the presence of $s c p B$ and rib virulence genes in these isolates. We screened 203 pregnant women attending the maternity Hospital of Ain Shams University using vaginal sampling. Isolation was done on CHROMagar ${ }^{\mathrm{TM}}$ Strep B and sheep blood agar plates then identified via colony characters, Gram stain, test for catalase production, Christie-Atkins-Munch-Petersen (CAMP) test, test for hippurate hydrolysis and latex agglutination test. This was followed by an antibiotic susceptibility test. Finally, Detection of $s c p B$ and rib virulence genes by conventional PCR was done. Our study detected that the prevalence rate of GBS in involved pregnant women was $\mathbf{1 1 . 3 3 \%}$. A statistically significant association between colonization and history of spontaneous abortion and preterm labor was observed. CHROMagar ${ }^{\mathrm{TM}}$ Strep B showed the same sensitivity of sheep blood agar with extensive effort to isolate suspected GBS colonies from blood agar. GBS was $\mathbf{1 0 0 \%}$ sensitive to levofloxacin, linezolid, cefepime, ceftaroline and ceftriaxone. Also, it was highly sensitive to vancomycin (91.3\%). Sensitivity to clindamycin, azithromycin, penicillin and ampicillin was $(21.70 \%, 21.70 \%, 47.80 \%, 47.80 \%)$ respectively. The least sensitivity of GBS was to erythromycin ( $8.7 \%)$. All isolates possessed the $s c p B$ gene $(100 \%)$ while only 18 isolates $(78.26 \%)$ had the rib gene.
\end{abstract}

Keywords: Group B streptococcus (GBS), CHROMagar ${ }^{\mathrm{TM}}$ Strep B, scpB, rib, virulence genes

*Correspondence: dr.nohagad@yahoo.com; +20 01096263842

(Received: June 20, 2021; accepted: August 05, 2021)

Citation: Abdallah NG, Ali FM, Adel LA, Elkotb AM, Ibrahim WA. Prevalence, Resistance Profile and Virulence Genes of Streptococcus agalactiae Colonizing Near-term Pregnant Women Attending Ain Shams University Hospital. J Pure Appl Microbiol. 2021; 15(3):1490-1500. doi: 10.22207/JPAM.15.3.43

(C) The Author(s) 2021. Open Access. This article is distributed under the terms of the Creative Commons Attribution 4.0 International License which permits unrestricted use, sharing, distribution, and reproduction in any medium, provided you give appropriate credit to the original author(s) and the source, provide a link to the Creative Commons license, and indicate if changes were made. 


\section{INTRODUCTION}

GBS is detected in $10-30 \%$ of pregnant women as a colonizing agent in the vagina and/ or rectum. The infants of these women may be at high risk of developing disease if they exposed to this bacteria before or after birth ${ }^{1,2}$.

Early-onset infection, the most prevalent kind of newborn GBS disease, and late-onset infection are the two types of GBS infections in neonates. The early-onset infection occurs in neonates under the age of seven days, while the late-onset infection occurs in those aged seven to ninety days ${ }^{3,4}$.

By preventing GBS transmission from mother to infant, intrapartum antibiotic prophylaxis (IAP) can minimize the risk of GBS neonatal illness. The Centers for Disease Control and Prevention (CDC) recommended two methods for detecting pregnant women, which were first published in 1996 and subsequently revised in 2002 and 2010: either a risk-based method of detecting clinical risk factors for newborn illness and administering IAP to all cases demonstrating any of these risk factors, or a universal screening for GBS by obtaining rectovaginal cultures between 35 and 37 weeks of pregnancy ${ }^{5,6}$.

GBS is still responsive to penicillin and most beta lactam antibiotics, but some investigations have found that GBS susceptibility to penicillin has decreased ${ }^{7}$.

Alternative antibiotics such as vancomycin, clindamycin, and erythromycin are given to pregnant women who are allergic to penicillin. Emerging clindamycin and erythromycin resistance strains have been found in several parts of the world, including Egypt ${ }^{8}$.

However, available data suggests that erythromycin and clindamycin given to pregnant women may not reliably reach foetal tissues, and cefazolin may be a suitable alternative for patients who do not have a severe penicillin allergy ${ }^{5}$.

GBS strains are able to cause infections not only because of the development of resistance but also due to their virulence traits. The most important virulence factor is capsule, but other virulence factors include; surface protein Rib \& C5a peptidase ${ }^{9}$.

A substantial percentage of GBS strains, that have caused invasive infections in newborns, have the invasin rib protein, which is generated by the rib gene ${ }^{9,10}$.

C5a peptidase is a surface enzyme that can deactivate the human complement component C5a. The $s c p B$ (Streptococcal C5a Peptidase) gene encodes it, and it may be horizontally transmitted between pyogenic streptococci. C5a peptidase also makes GBS strains adhere to epithelial cells and extracellular matrix proteins easier ${ }^{11}$.

$S c p B$ gene is used as a standard gene for checking prevalence rate of GBS in pregnant women via polymerase chain reaction (PCR) due to its high prevalence among GBS human isolates ${ }^{12}$. Only strains with the $\operatorname{spB} B$ gene are thought to be infective to humans ${ }^{11}$.

These virulence proteins have been studied as possible vaccine candidates due to their capacity to generate a strong protective immunity against GBS infections ${ }^{13}$.

The sensitivity of cultures in identifying GBS colonisation ranges from $54-87 \%$, results are acquired in 36 to 72 hours, and identification of colonies, which are not necessarily beta-hemolytic, requires an experienced technician ${ }^{14}$.

Rapid methods of identifying GBS colonisation in pregnant women have been available in recent years, such as DNA probes and nucleic acid amplification tests (NAAT) like $\mathrm{PCR}$, and they have become the primary method of research. PCR is said to be highly sensitive and specific, with results appearing in 30 to 45 minutes ${ }^{14}$.

The aim of this study was to investigate how common GBS was in pregnant women, as well as the antibiotic sensitivity pattern of isolated GBS colonies and if the $\operatorname{sp} B$ and rib virulence genes were present.

\section{SUBJECTS AND METHODOLOGY Subjects}

The current study was a cross-sectional observational study done on 203 pregnant women who attended the Maternity Hospital outpatient clinic at the Faculty of Medicine, Ain Shams University Hospital in Cairo, Egypt, From September 2020 to February 2021. The mean age among cases was $26.2 \pm 5.9$ and the mean gestational age was $36.1 \pm 0.8$. Before taking samples, all subjects gave their informed consent, 
as required by the "Ethical Committee of Scientific Research of the Faculty of Medicine, Ain Shams University, Cairo, Egypt," and in accordance with "The World Medical Association's Code of Ethics (Declaration of Helsinki) for human experiments." Inclusion criteria

Women between 35 and 37 weeks gestation, women with a history of complications in past pregnancies, such as termination, preterm birth, prolonged rupture of membranes for 18 hours or more, intrapartum fever of $38^{\circ} \mathrm{C}$ or more, and women with a previous GBS infected baby were all included in the study.

\section{Exclusion criteria}

Taking antibiotics within the previous month for any reason, a woman in labour ("The candidate has regular and painful uterine contractions causing cervical dilatation and effacement"), a woman with infection involving urinary tract or vagina in the current pregnancy, vaginal douche 24 hours before screening, or vaginal bleeding were all reasons for exclusion from the study.

\section{Methods}

The steps in the research process were as follows:

1. Obtaining a complete medical history as well as clinical data

2. Specimen collection, transport and processing

3. Detection of antimicrobial susceptibility pattern in GBS strains

4. Molecular test (PCR) for the detection of $s c p B$ $\&$ rib genes

5. Analyzing data

The following procedures were performed on all of the enrolled patients:

Obtaining a complete medical history as well as clinical data

Patient's age, parity, gestational age , obstetric complications, any current medical or surgical diseases and any current medications.

Specimen collection, transport and processing

A sterile cotton swab was rotated against the vaginal wall for vaginal sample then inoculated directly onto CHROMagar ${ }^{\mathrm{TM}}$ Strep B (CHROMagar microbiology, France) as well as a sheep blood agar. CHROMagar $^{\text {TM }}$ Strep B medium selectively inhibits most of normal flora bacteria and yeasts. On this medium, GBS in aerobic conditions produce characteristic pink mauve colonies ${ }^{15}$.

The plates were immediately transported at room temperature to laboratory, Microbiology department, Faculty of medecine, ASU to be processed according to the recommendations of the American Society for Microbiology (ASM)16. Incubation was done aerobically at $37^{\circ} \mathrm{C}$ for 24 hours ${ }^{15}$.

The following conventional techniques were used to identify the isolates: colonial morphology on CHROMagar ${ }^{\mathrm{TM}}$ Strep B, haemolysis on blood agar, Gram staining, catalase test, CAMP test, hippurate hydrolysis and latex agglutination test with pecific antisera ${ }^{16}$.

\section{Detection of antimicrobial susceptibility pattern} in GBS strains

Antibiotic susceptibility testing was done for the $23 \mathrm{GBS}$ isolates by disk diffusion technique on Mueller-Hinton agar containing 5\% sheep blood according to Clinical Laboratory Standards Institute (CLSI) guidelines ${ }^{17}$.

The used antibiotics disks were Penicillin

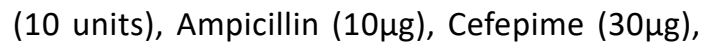
Ceftriaxone $(30 \mu \mathrm{g})$, Cefotaxime $(30 \mu \mathrm{g})$, Vancomycin $(30 \mu \mathrm{g})$, Levofloxacin $(5 \mu \mathrm{g})$, Linezolid $(30 \mu \mathrm{g})$, Clindamycin $(2 \mu \mathrm{g})$ and Erythromycin $(15 \mu \mathrm{g})$. The control starin used was S. pneumoniae ATCC $49619^{17}$.

Double-disk diffusion method (D-zone test) to detect erythromycin resistance phenotype was performed ${ }^{18,19}$.

\section{Molecular test (PCR)}

Conventional PCR was done for the detection of $\triangle c p B$ and rib genes. DNA extraction was performed using Qiagen DNeasy (Qiagen, USA) according to the manufacturer instructions. Amplification of $s c p B$ gene was carried out using the Forward primer: ACAACGGAA GGCGCTACTGTTC and the Reverse primer: ACCTGGTGTTTGACCTGAACTA (Invitrogen by Life Technologies, Thermo Fisher Scientific Inc., USA), While amplification of rib gene was carried out using the Forward primer: CAGGAAGTG CTGTTACGTTAA AC and the Reverse primer: CGTCCCATTTAGGGTTCTTCC (Invitrogen by Life Technologies, Thermo Fisher Scientific Inc., USA). An initial denaturation phase at $95^{\circ} \mathrm{C}$ for 2 minutes was followed by 35 amplification cycles of denaturation at $95^{\circ} \mathrm{C}$ for $30 \mathrm{~s}$, annealing at $55^{\circ} \mathrm{C}$ for 
Table 1. Comparison between GBS positive and negative as regard age and gestational age

\begin{tabular}{|c|c|c|c|c|c|c|}
\hline & \multicolumn{4}{|c|}{ GBS } & \multirow[t]{3}{*}{ P-value ${ }^{e}$} & \multirow[t]{3}{*}{ Sig } \\
\hline & \multicolumn{2}{|c|}{ Negative } & \multicolumn{2}{|c|}{ Positive } & & \\
\hline & Mean & $\pm S D$ & Mean & $\pm S D$ & & \\
\hline Age & $26.23 \mathrm{a}$ & 5.98 & $26.70 \mathrm{~b}$ & 5.60 & $0.72 *$ & NS \\
\hline Gestational age & $36.11 \mathrm{c}$ & 0.87 & $36.43 \mathrm{~d}$ & 0.79 & $0.09 *$ & NS \\
\hline
\end{tabular}

*Student t test; Sig: significance, NS: non-significant

Table 2. Relationship between parity and GBS result among cases

\begin{tabular}{|c|c|c|c|c|c|c|c|c|c|}
\hline & & \multicolumn{6}{|c|}{ Parity } & \multirow[t]{3}{*}{ P-value ${ }^{a}$} & \multirow[t]{3}{*}{ Sig } \\
\hline & & \multicolumn{2}{|c|}{$\mathrm{PO}$} & \multicolumn{2}{|c|}{ P1-2 } & \multicolumn{2}{|c|}{ P3-4 } & & \\
\hline & & $\mathrm{N}$ & $\%$ & $\mathrm{~N}$ & $\%$ & $\mathrm{~N}$ & $\%$ & & \\
\hline \multirow[t]{2}{*}{ GBS } & Negative & 40 & $93.0 \%$ & 100 & $87.0 \%$ & 40 & $88.9 \%$ & 0.587 & NS \\
\hline & Positive & 3 & $7.0 \%$ & 15 & $13.0 \%$ & 5 & $11.1 \%$ & & \\
\hline
\end{tabular}

*Chi-Square Tests; N: Number, Sig: significance, NS: non-significant

Table 3. Relationship between Previous abortion and GBS result among cases

\begin{tabular}{|c|c|c|c|c|c|c|c|}
\hline & & \multicolumn{4}{|c|}{ Previous abortion } & \multirow{3}{*}{ P-value } & \multirow[t]{3}{*}{ Sig } \\
\hline & & \multicolumn{2}{|c|}{ No } & \multicolumn{2}{|c|}{ Yes } & & \\
\hline & & $\mathrm{N}$ & $\%$ & $\mathrm{~N}$ & $\%$ & & \\
\hline \multirow[t]{2}{*}{ GBS } & Negative & 161 & $91.5 \%$ & 19 & $70.4 \%$ & $0.004 *$ & HS \\
\hline & Positive & 15 & $8.5 \%$ & 8 & $29.6 \%$ & & \\
\hline
\end{tabular}

*Fisher exact test; N: Number, Sig: significance, HS: Highly-significant

$60 \mathrm{~s}$, extension at $72^{\circ} \mathrm{C}$ for $60 \mathrm{~s}$, and a final cycle of extension at $72^{\circ} \mathrm{C}$ for 10 minutes. Every reaction includes negative extraction and master mix controls. The size of the amplicons was confirmed by electrophoresis on $1 \%$ agarose gel at $255 \mathrm{bp}$ for $s c p B$ gene and 369 for rib gene ${ }^{18}$.

\section{Data assessment}

The IBM Statistical Program for Social Science (SPSS) version 25.0 was used to analyse the data. The mean and standard deviation were used to convey quantitative data. Frequency and percentage were used to convey qualitative data.

\section{RESULTS}

Positive GBS result was present in $11.3 \%$ of case ( 23 cases out of 203 total candidates). The prevalence of GBS among cases as regard age and gestational age

The mean age in negative GBS cases was
$26.23 \pm 5.98$ years while it was $26.70 \pm 5.6$ in positive cases. The mean gestational age was $36.11 \pm 0.87$ in negative cases while it was $36.43 \pm 0.79$ in positive cases. There was no significant difference between negative and positive GBS cases as regard age and gestational age $(P$ value $>0.05$ ) as shown in Table 1.

The prevalence of GBS among cases as regard Obstetric characteristics of the participants

There was no significant distinction among cases with different parity as regard the GBS result ( $P$ value $>0.05$ ); $7 \%, 13 \%$ and $11.1 \%$ of P0, P1-2 and P3-4 cases were positive for GBS result respectively as shown in Table 2 .

On the other hand, there was a highly significant difference between cases with and without history of previous abortion as regard the GBS result ( $P$ value $<0.05$ ); $29.6 \%$ of cases with 
Table 4. Relationship between Previous preterm birth and GBS result among cases

\begin{tabular}{|c|c|c|c|c|c|c|c|c|}
\hline & & \multicolumn{4}{|c|}{ Previous preterm birth } & & \multirow[t]{3}{*}{ P-value ${ }^{a}$} & \multirow[t]{3}{*}{ Sig } \\
\hline & & \multicolumn{2}{|c|}{ No } & \multicolumn{2}{|c|}{ Yes } & & & \\
\hline & & $\mathrm{N}$ & $\%$ & $\mathrm{~N}$ & $\%$ & & & \\
\hline \multirow[t]{2}{*}{ GBS } & Negative & 171 & $91.4 \%$ & 9 & $56.3 \%$ & $0.001^{*}$ & HS & \\
\hline & Positive & 16 & $8.6 \%$ & 7 & $43.8 \%$ & & & \\
\hline
\end{tabular}

*Fisher exact test; N: Number, Sig: significance, HS: Highly-significant

Table 5. Description of Antibiotic sensitivity for positive GBS cases

\begin{tabular}{lcc}
\hline & N & $\%$ \\
\hline Penicillin & 23 & $100 \%$ \\
Ampicillin & 23 & $100 \%$ \\
Cefepime & 23 & $100 \%$ \\
Ceftriaxone & 23 & $100 \%$ \\
Cefotaxime & 23 & $100 \%$ \\
Vancomycin & 23 & $100 \%$ \\
Levofloxacin & 23 & $100 \%$ \\
Linezolid & 23 & $100 \%$ \\
Clindamycin & 17 & $73.91 \%$ \\
Erythromycin & 14 & $60.86 \%$ \\
\hline
\end{tabular}

$\mathrm{N}$ : Number

Table 6. $s c p B$ and Rib genes in positive GBS cases

\begin{tabular}{lccc}
\hline & & $\mathrm{N}$ & $\%$ \\
\hline \multirow{2}{*}{$s c p B$} & Negative & 0 & $0.0 \%$ \\
& Positive & 23 & $100.0 \%$ \\
\multirow{2}{*}{ rib } & Negative & 5 & $21.7 \%$ \\
& Positive & 18 & $78.3 \%$ \\
\hline
\end{tabular}

$\mathrm{N}$ : Number

previous abortion had positive GBS compared to $8.5 \%$ only of cases without previous abortion as shown in Table 3.

Moreover, there was a highly significant difference between cases with and without history of previous preterm birth as regard the GBS result ( $P$ value $<0.05$ ); $43.8 \%$ of cases with previous preterm birth had positive GBS compared to $8.6 \%$ only of cases without previous preterm birth as shown in Table 4.

\section{Culture and biochemical reaction results}

Direct plating of GBS from vaginal specimens onto CHROMagar strep B or sheep blood agar was similarly sensitive in detecting GBS.
All pink mauve colonies on CHROMagar strept B were proven to be GBS. On the other hand, not all beta hemolytic colonies or tiny nonhemolytic catalase negative colonies on sheep blood agar proved to be GBS, and the isolation of the suspected GBS colonies took greater work.

The CAMP test, Hippurate test, and latex agglutination assay (Oxoid, UK) were used to confirm the presence of GBS in all gram positive and catalase negative cocci isolates.

\section{Antimicrobial susceptibility testing results}

GBS isolates were $100 \%$ sensitive to penicillin, ampicillin, cefepime, ceftriaxone, cefotaxime, vancomycin, levofloxacin and linezolid. Sensitivity to clindamycin and erythromycin was (73.91\%, 60.86\%) respectively. Antimicrobial susceptibility results are shown in Table 5.

Concerning D-zone test result, $44.4 \%$ (4/9) of erythromycin resistant isolates were found to have CMLSB (constitutive macrolide lincosamide Streptogramin B resistance), while iMLSB resistance (inducible macrolide lincosamide Streptogramin B resistance) was detected in three isolates (3/9; 33.3\%). M phenotype (erythromycin resistant and clindamycin susceptible) was reported in two isolates $(2 / 9 ; 22.2 \%)$.

PCR results

$\operatorname{scp} B$ gene was found in all GBS isolates (100\%) while only 18 isolates tested positive for the rib gene (78.26\%) as shown in Table 6.

\section{DISCUSSION}

Neonatal infections are linked to GBS rectal or vaginal colonisation during pregnancy. Thus, screening pregnant women for GBS colonisation and determining the isolates' antibiotic susceptibility are critical for the prevention and treatment of streptococcal infections in both mothers and their newborns ${ }^{20}$. 
The aim of this study was to investigate how common GBS was in pregnant women, as well as the antibiotic sensitivity pattern of isolated GBS colonies and if the $s c p B$ and rib virulence genes were present.

The study included 203 pregnant females. Vaginal swab samples from the involved pregnant women were collected for culture. the mean age among cases was $26.2 \pm 5.9$; the mean gestational age was $36.1 \pm 0.8$. About $57 \%$ of cases were P12 ; the majority of cases ( $86.7 \%$ ) had no previous abortion, while about $8 \%$ had previous preterm birth.

The prevalence rate of GBS detected among pregnant women was $11.33 \%$. Our findings agreed with those of many countries that also detected a prevalence rate ranging between $(10-30 \%)$ as Blantyre $(16.5 \%)^{21}$, Egypt $(17.89 \%)^{22}$, Kuwait $(16.4 \%)^{23}$, Zimbabwe $(21 \%)^{24}$, Tanzania $(23 \%)^{25}$, Belgium $(22 \%)^{26}$, Netherlands $(21 \%)^{27}$, Germany $(23 \%)^{28}$ and Sweden $(25.4 \%)^{29}$.

However, when compared to other countries, such as Mozambique $(1.8 \%)^{30}$, Iran $(4.8 \%)^{31}$, the Philippines $(7.5 \%)^{32}$, and France $(8 \%)^{33}$, the prevalence rate of this study is greater. Many factors, such as gestational age at culturing, variations in culture sites, sensitivity of culture methods, various demographics, personal cleanliness, or intensive use of antiseptics or antibiotics, might explain the varied prevalence rates $^{27}$.

Our findings revealed that the majority of GBS positive pregnant women were between the ages of 20 and 30, and that GBS colonisation is more common among pregnant women in the $37^{\text {th }}$ week of pregnancy, but the frequency of GBS colonisation among different age and gestational age groups was not statistically significant.

This agrees with findings reported from other studies that showed that the sociodemographic variables don't affect GBS colonization rates ${ }^{34-36}$. However, other studies found a rise in GBS colonization as the age of the candidates increases ${ }^{7,25,37}$.

Other studies from Africa revealed that the majority of GBS positive pregnant women were between the ages of 20 and 30, and this was found statistically significant ${ }^{18,24}$.
Some studies reported that gestational age of women is a risk factor to GBS colonization. A higher prevalence was detected among women between 35 to 37 weeks 38 and increases as the gestational age increases ${ }^{39}$.

In the present study, a statistically significant link was detected between GBS colonisation and a history of spontaneous abortion and premature labour.

Similar findings reported in studies conducted by Feikin et al. ${ }^{40}$, McDonald \& Chambers $^{41}$, Tsolia et al. ${ }^{42}$ and Kimura et al. ${ }^{43}$ who found that GBS colonisation was much more common in women with a clinical history of premature birth and spontaneous abortion.

Garland et al. ${ }^{44}$ and El Aila et al. ${ }^{45}$ found no link between GBS colonisation and preterm labour, early membrane rupture, or spontaneous abortion.

Regarding parity as a risk factor, in our study there was no significant difference between cases with different parity as regard GBS result. Various studies agreed with our findings and noted that no significant differences in colonization rates were found on the basis of parity ${ }^{46,47}$.

On the contrary other studies found that high parity was sometimes associated with increased GBS colonization ${ }^{25}$.

Surprisingly, in some studies women with a lower parity were more colonized with GBS than women with a higher parity ${ }^{27,48}$. The explanation of this variability is unclear and necessitate further research.

Vaginal flora contains abundant microorganisms, so the isolation of GBS won't be easy and the overgrowth of other organisms should be avoided. This mission can be aided by chromogenic media that discriminate GBS colonies. The $\mathrm{CDC}$ recommendations published in 2002 encouraged the development of these media in order to increase the accuracy of culture results and make culture processing easier ${ }^{6}$.

In our study, a selective chromogenic medium (CHROMagar ${ }^{\mathrm{TM}}$ Strep B) was used. It enabled the identification of GBS as characteristic pink mauve colonies by direct visual inspection within 24 hours. Other bacterial species may be inhibited, or colonies of a different colour may form (e.g. blue, colorless). 
It also allowed all GBS strains to grow in an aerobic environment, regardless of their haemolytic characteristics.

Both CHROMagar ${ }^{\mathrm{TM}}$ Strep B and sheep blood agar performed similarly, yielding the same results. The work to isolate suspected GBS colonies from blood agar, on the other hand, was quite intensive. Similar findings were reported in studies accomplished by Sadaka et al. ${ }^{18}$, El Aila et al. ${ }^{26}$ and Tazi et al. ${ }^{49,50}$.

In contrast to our results, some studies reported lower sensitivity of blood agar in comparison to CHROMagar ${ }^{\text {TM }}$ Strep $\mathrm{B}^{15,51,52}$.

Sensitivity to penicillin and ampicillin is highly variable in different studies. In our study it was $100 \%$ to both antibiotics. This coincides with findings of Mohammed et al. ${ }^{36}$, Brandon and Dowzicky ${ }^{53}$, Adawaye et al. ${ }^{54}$, Arif et al. ${ }^{55}$ and Mengist et al. ${ }^{56}$, who found that GBS isolates were $100 \%$ susceptible to both penicillin and ampicillin. Our results are different from those of El Aila et al. ${ }^{45}$, Kimura et al. ${ }^{57}$, Longtin et al. ${ }^{58}$ and Banno et al. ${ }^{59}$ who detected reduced susceptibility to both penicillin and ampicillin.

Non of the isolates was resistant to cefepime,ceftriaxone and cefotaxime. This concides with results of Sadaka et al. ${ }^{18}$, Elikwu et al..$^{60}$, Ji et al. ${ }^{61}$ and Gomi et al. ${ }^{62}$ who detected $100 \%$ sensitivity to these antibiotics.

On the other hand ceftriaxone and cefotaxime non-susceptible GBS isolates were found in studies by Simoes et al. ${ }^{63}$, Kitamura et al. ${ }^{64}$ and Mudzana et al..$^{65}$.

GBS isolates in our study were $100 \%$ sensitive to vancomycin. This agrees with many studies who also reported the same result $\mathrm{t}^{18,48,55}$.

On the other hand, El Aila et al. ${ }^{45}$ and Jisuei et al. ${ }^{66}$ detected reduced sensitivity of the isolates to vancomycin ( $76 \%$ and $80 \%$ respectively). In our study, GBS was $100 \%$ sensitive to levofloxacin. The same findings were detected by Hannoun et al. ${ }^{10}$ and Eskandarian et al. ${ }^{67}$ and.On the contrary Sadaka et al. ${ }^{18}$ reported that only $56.6 \%$ of isolates were sensitive to levofloxacin.

Our isolates were also $100 \%$ sensitive to linezolid which is in consistent with results of Sadaka et al. ${ }^{18}$ and Arif et al..$^{55}$.

Sensitivity to clindamycin was $73.91 \%$. This was quite similar to Sadaka et al. ${ }^{18}$, Arif et al. ${ }^{55}$, Ghanbarzadeh et al. ${ }^{68}$ and who reported the sensitivity to clindamycin as $75 \%, 76.92 \%$ and $85 \%$ respectively .

This result is higher than that of El Aila et al..$^{45}$ who detected $31 \%$ sensitivity to clindamycin. On the other hand, non of the isolates was sensitive to clindamycin in a study conducted by Onipede et al. ${ }^{7}$.

In our study GBS sensitivity to erythromycin was (60.86\%). This agrees with $\mathrm{El}$ Aila et al. ${ }^{45}$, Arif et al. ${ }^{55}$ and Ghanbarzadeh et al. ${ }^{68}$ who detected reduced sensitivity to erythromycin. On the other hand other studies detected $100 \%$ sensitivity to erythromycin ${ }^{36,54,56}$.

The prevalence of virulence genes, namely $\operatorname{scp} B$ and rib among the 23 strains detected in our study is high. Other unknown virulence traits may be also present as the pathogenicity of GBS is related to multiple genes.

In our study, the $\operatorname{spB}$ gene was found in all of the isolates. Some studies suggest that the presence of the $s c p B$ gene in GBS human isolates is required, and only strains carrying the $\operatorname{sp} B$ gene are infectious to humans ${ }^{69}$.

This result agrees with Sadaka et al. ${ }^{18}$, Dmitriev et al. ${ }^{69}$, Dutra et al. ${ }^{70}$ and Bobadilla ${ }^{71}$ who also detected the presence of $s c p B$ gene in all isolates. However, other studies by Hannoun et al. ${ }^{10}$, Mudzana et al. ${ }^{65}$ and Lysakowska et al. ${ }^{11}$ detected $s c p B$ in $94.7 \%, 90.1 \%$ and $92.5 \%$ of human isolates respectively.

On the other hand, the presence of rib gene was confirmed only in 18 isolates (78.26\%). This result concides with Sadaka et al. ${ }^{18}$ and Mudzana et al. ${ }^{65}$ who detected the presence of rib gene in $79.2 \%$ and $69.8 \%$ of isolates respectively, while Hannoun et al. ${ }^{10}$ and Lysakowska et al. ${ }^{11}$ detected this gene in only $35 \%$ and $33 \%$ of isolates respectively.

The inability to follow up the pregnant women who had a positive GBS culture to ascertain the rate of newborn infection or other complications was the most significant drawback of our study. Another disadvantage is that due to funding constraints, GBS serotyping was not done.

\section{CONCLUSION}

Screening is a quick and sensitive procedure that is both helpful and cost-effective, 
particularly for individuals who present at term with unclear GBS colonisation status as well as those who are in preterm labour. Further research on the prevalence of virulence genes of GBS among pregnant women is required to obtain complete data about the pathogenicity of GBS bacteria and support vaccine development in the near future.

\section{ACKNOWLEDGMENTS}

None.

\section{CONFLICT OF INTEREST}

The authors declare that there is no conflict of interest.

\section{AUTHORS' CONTRIBUTION}

All authors have made substantial contributions to conception and design of the study. AME and NG contributed to samples collection and acquisition of patients' data. WAI and NG contributed to all laboratory work with analysis and interpretation of data. LA, WAI, AME and NG contributed to drafting the article. FM, LA and WAI and contributed to revising the draft critically for important intellectual and scientific content. AME revised the clinical content. All authors provided final approval of the version to be published.

\section{FUNDING}

None.

\section{DATA AVAILABILITY}

All datasets generated or analyzed during this study are included in the manuscript.

\section{ETHICS STATEMENT}

The study was carried out in accordance to the recommendations of the Ethical Committee of Scientific Research of Faculty of Medicine, Ain Shams University, Cairo, Egypt (No. FMASU M D 215/2018) and according to The Code of Ethics of the World Medical Association (Declaration of Helsinki) for experiments in humans.

\section{REFERENCES}

1. Spellerberg B. Pathogenesis of neonatal Streptococcus agalactiae infections. Microbes Infect. 2000;2(14):1733-1742. doi: 10.1016/S12864579(00)01328-9

2. Edwards MS, Nizet V, Baker CJ. Group B Streptococcal
Infections. In: Infectious Diseases of the Fetus and Newborn Infant, $7^{\text {th }}$ ed, Remington JS, Klein JO, Wilson CB, et al (Eds), Elsevier Saunders, Philadelphia. 2011:419. doi: 10.1016/B978-1-4160-6400-8.00012-2

3. Schuchat A. Epidemiology of Group B Streptococcal disease in the United States: shifting paradigms. Clin Microbiol Rev. 1998;11(3):497-513. doi: 10.1128/ CMR.11.3.497

4. Capan M, Mombo-Ngoma G , Akerey-Diop D, et al. Epidemiology and management of group $B$ streptococcal colonization during pregnancy in Africa. Wien Klin Wochenschr. 2012;124(Suppl 3):14-16. doi: 10.1007/s00508-012-0239-5

5. Verani JR, McGee L, Schrag SJ. Prevention of perinatal group $B$ streptococcal disease, Division of Bacterial Diseases, National Center for Immunization and Respiratory Diseases, Centers for Disease Control and Prevention (CDC). MMWR Recomm Rep. 2010;59(10):1-36.

6. Schrag S, Gorwitz R, Fultz-Butts K, Schuchat A. Prevention of perinatal group $B$ streptococcal disease. Revised guidelines from CDC. MMWR Recomm Rep. 2002;51:1-22.

7. Onipede A, Adefusi O, Adeyemi A, Adejuyigbe E, Oyelese A, Ogunniyi T. Group B Streptococcus carriage during late pregnancy in Ile-Ife, Nigeria. Afr J Clin Exp Microbiol. 2012;13(3):135-143. doi: 10.4314/ajcem. v13i3.2

8. Shabayek S, Abdalla S. Macrolide- and tetracyclineresistance determinants of colonizing group $B$ streptococcus in women in Egypt. J Med Microbiol. 2014;63(10):1324-1327. doi: 10.1099/jmm.0.0770570

9. Sadowy E, Matynia B, Hryniewicz W. Population structure, virulence factors and resistance determinants of invasive, non-invasive and colonizing Streptococcus agalactiae in Poland. J Antimicrob Chemother. 2010;65(9):1907-1914. doi: 10.1093/jac/ dkq230

10. Hannoun A, Shehab M, Khairallah MT, et al. Correlation between group B streptococcal genotypes, their antimicrobial resistance profiles, and virulence genes among pregnant women in Lebanon. Int J Microbiol. 2009. doi: $10.1155 / 2009 / 796512$

11. Lysakowska ME, Kalinka J , Bigos M, Prosniewska M, Wasiela $M$. Occurrence of virulence genes among $S$. agalactiae isolates from vagina and anus of pregnant women - a pilot study. Archives of Perinatal Medicine. 2011;17(4):229-234.

12. Rallu F, Barriga P, Scrivo C, Martel-Laferriere V, Laferriere C. Sensitivities of antigen detection and PCR assays greatly increased compared to that of the standard culture method for screening for group B streptococcus carriage in pregnant women. J Clin Microbiol. 2006;44(3):725-728. doi: 10.1128/ JCM.44.3.725-728.2006

13. Maione D, Margarit I, Rinaudo CD, et al. Identification of a universal Group B streptococcus vaccine by multiple genome screen. Science. 2005;309(5731):148-150. doi: 10.1126/science.1109869

14. Mousavi SM, Hosseini SM, Mashouf RY, Arabestani 
MR. Identification of Group B Streptococci using $16 \mathrm{~S}$ rRNA, $c f b, s c p B$, and atr genes in pregnant women by PCR. Acta Medica Iranica.2016;54(12):765-770.

15. Poisson DM, Chandemerle M, Guinard J, Evrard ML, Naydenova D, Mesnard L. Evaluation of CHROMagar Strep B: a new chromogenic agar medium for aerobic detection of Group B Streptococci in perinatal samples. J Microbiol Methods. 2010;82(3):238-242. doi: 10.1016/j.mimet.2010.06.008

16. Filkins L, Hauser JR, Robinson-Dunn B, Tibbetts $R$, Boyanton BL, Revell P. American Society for Microbiology Provides 2020 Guidelines for Detection and Identification of Group B Streptococcus. J Clin Microbiol. 2020;59(1):e01230-20. doi: 10.1128/ JCM.01230-20

17. Clinical and Laboratory Standards Institute, CLSI. Performance standards for antimicrobial susceptibility testing, 30 $0^{\text {th }}$ ed, Wayne, PA. 2020.

18. Sadaka SM, Aly HA, Meheissen MA, Orief YI, Arafa BM. Group B streptococcal carriage, antimicrobial susceptibility, and virulence related genes among pregnant women in Alexandria, Egypt. Alexandria Journal of Medicine. 2018;54(1):69-76. doi: 10.1016/j. ajme.2017.01.003

19. Gizachew M, Tiruneh M, Moges F, Adefris M, Tigabu Z, Tessema B. Newborn colonization and antibiotic susceptibility patterns of Streptococcus agalactiae at the University of Gondar Referral Hospital, Northwest Ethiopia. BMC Pediatr. 2018;18(1):378. doi: 10.1186/ s12887-018-1350-1

20. Javanmanesh F, Eshraghi N. Prevalence of positive recto-vaginal culture for Group B streptococcus in pregnant women at 35-37 weeks of gestation. Med J Islam Repub Iran. 2013;27(1):7-11.

21. Dzowela T, Komolafe O, Lgbigbia A. Prevalence of group B Streptococcus Colonization in antenatal women at the Queen Elizabeth Central Hospital Blantyre-a preliminary study. Malawi Medical Journal. 2005;17(3):97-99. doi: 10.4314/mmj.v17i3.10888

22. Elbaradie S, Mahmoud M, Farid M. Maternal and neonatal screening for Group B streptococci by SCP $B$ gene based PCR: a preliminary study. Indian J Med Microbiol. 2009;27(1):17-21. doi: 10.1016/S02550857(21)01746-1

23. Al-Sweih N, Maiyegun S, Diejomaoh M, et al. Streptococcus agalactiae (Group B Streptococci) Carriage in Late Pregnancy in Kuwait. Medical Principles and Practice. 2004;13(1):10-14. doi: 10.1159/000074044

24. Mavenyengwa R, Afset J, Schei B, et al. Group B Streptococcus colonization during pregnancy and maternal-fetal transmission in Zimbabwe. Acta Obstetricia et Gynecologica Scandinavica. 2010; 89(2):250-255. doi: 10.3109/00016340903398029

25. Joachim A, Matee MI, Massawe FA, Lyamuya EF. Maternal and neonatal colonization of group $B$ Streptococcus at Muhimbili national hospital in Dares Salaam, Tanzania: prevalence, risk factors and antimicrobial resistance. BMC Public Health. 2009;9:437. doi: 10.1186/1471-2458-9-437

26. El Aila N, Tency I, Claeys G, et al. Comparison of different sampling techniques and of different culture methods for detection of group B streptococcus carriage in pregnant women. BMC Infectious Diseases. 2010;10:285. doi: 10.1186/1471-2334-10-285

27. Valkenburg-van den Berg AW, Sprij AJ, Oostvogel PM, et al. Prevalence of colonisation with group $B$ Streptococci in pregnant women of a multi-ethnic population in The Netherlands. Europ J Obstet Gynec Reprod Biol. 2006;124(2):178-183. doi: 10.1016/j. ejogrb.2005.06.007

28. Von Both U, John A, Fluegge K, Siedler A, Berner R. Molecular epidemiology of invasive neonatal Streptococcus agalactiae isolates in Germany. Pediatr Infect Dis J. 2008;27(10):903-906. doi: 10.1097/ INF.0b013e318178d1ff

29. Hakansson S, Axemo P, Bremme K, et al. Group B streptococcal carriage in Sweden: a national study on risk factors for mother and infant colonisation. Acta obstetricia et gynecologica Scandinavica. 2008;87(1):50-58. doi: 10.1080/00016340701802888

30. De Steenwinkel FD, Tak HV, Muller AE, Nouwen JL, Oostvogel PM, Mocumbi SM. Low carriage rate of group B streptococcus in pregnant women in Maputo, Mozambique. Trop Med Int Health. 2008;13(3):427429. doi: 10.1111/j.1365-3156.2008.02018.x

31. Shirazi M, Abbariki E, Hafizi A, Shahbazi F, Bandari M, Dastgerdy $E$. The prevalence of group $B$ streptococcus colonization in Iranian pregnant women and its subsequent outcome. Int J Fertil Steril. 2014;7(4):267270.

32. Whitney CG, Daly S, Limpongsanurak S, Festin MR, Thinn KK, Chipato T, Global Network for Perinatal and Reproductive Health.The international infections in pregnancy study: Group B streptococcal colonization in pregnant women. J Matern Fetal Neonatal Med. 2004;15(4):267-274. doi: 10.1080/14767050410001668617

33. Van der Mee-Marquet $N$, Jouannet $C$, Domelier AS, Arnault L, Lartigue MF, Quentin R. Genetic diversity of Streptococcus agalactiae strains and density of vaginal carriage. J Med Microbiol. 2009;58(2):169-173. doi: 10.1099/jmm.0.005827-0

34. Jones N, Oliver K, Jones Y, Haines A, Crook D. Carriage of group $B$ streptococcus in pregnant women from Oxford, UK. J Clin Pathol. 2006;59(4):363-366. doi: 10.1136/jcp.2005.029058

35. Castellano-Filho DS, da Silva VL, Nascimento TC, de Toledo Vieira M, Diniz CG. Detection of Group B Streptococcus in Brazilian pregnant women and antimicrobial susceptibility patterns. Braz J Microbiol. 2010;41(4):1047-1055. doi: 10.1590/S151783822010000400024

36. Mohammed M, Asrat D, Woldeamanuel Y, Demissie A. Prevalence of group B Streptococcus colonization among pregnant women attending antenatal clinic of Hawassa Health Center, Hawassa, Ethiopia. Ethiop J Health Dev. 2012;26(1):36-42.

37. Donbraye-Emmanuel O, Okonko I, Donbraye E, et al. Isolation and characterization of Group B Streptococci and other pathogens among pregnant women in Ibadan, Southwestern Nigeria. J Appl Biosci. 2010;5902:1781-1792.

38. Doare KL, Jarju S, Darboe S, et al. Risk factors for group 
B Streptococcus colonisation and disease in Gambian women and their infants. J Infect. 2016;72(3):283-294. doi: 10.1016/j.jinf.2015.12.014

39. El-Kersh TA, Al-Nuaim LA, Kharfy TA, Al-Shammary FJ, Al-Saleh SS, Al-Zamel FA. Detection of genital colonization of group B streptococci during late pregnancy. Saudi Med J. 2002;23(1):56-61.

40. Feikin DR, Thorsen P, Zywicki S, Arpi M, Westergaard $J G$, Schuchat A. Association between colonization with group B streptococci during pregnancy and preterm delivery among Danish women. Am J Obstet Gynecol. 2001;184(3):427-433. doi: 10.1067/mob.2001.109936

41. McDonald HM, Chambers HM. Intrauterine infection and spontaneous midgestation abortion: is the spectrum of microorganisms similar to that in preterm labor? Infect Dis Obstet Gynecol. 2000;8(5-6):220227. doi: 10.1002/1098-0997(2000)8:5<220::AIDIDOG1022>3.0.CO;2-I

42. Tsolia M, Psoma M, Gavrili S, et al. Group B streptococcus colonization of Greek pregnant women and neonates: prevalence, risk factors and serotypes. Clin Microbiol Infect.2003;9(8):832-838. doi: 10.1046/j.1469-0691.2003.00662.x

43. Kimura K, Nagano N, Nagano Y, et al. Predominance of sequence type 1 group with serotype $\mathrm{VI}$ among group B streptococci with reduced penicillin susceptibility identified in Japan. J Antimicrob Chemother. 2011;66(11):2460-2464. doi: 10.1093/jac/dkr352

44. Garland SM, Kelly N, Ugoni AM. Is antenatal group B streptococcal carriage a predictor of adverse obstetric outcome? Infect Dis Obstet Gynecol. 2000;8(3-4):138142. doi: 10.1002/1098-0997(2000)8:3/4<138::AIDIDOG7>3.0.CO;2-6

45. Aila NE, Esleem SE, Elmanama A. Prevalence of Group B Streptococcus Colonization among Pregnant Women in Gaza strip, Palestine. IUG Journal of Natural Studies. 2017;25(3):1-12.

46. Eren A, Kucukercan M, Oguzoglu N, Unal N, Karateken A. The carriage of group B streptococci in Turkish pregnant women and its transmission rate in newborns and serotype distribution. Turk J Pediatr. 2005;47:2833.

47. Mansouri S, Ghasami E, Najad NS. Vaginal colonization of group B streptococci during late pregnancy in Southern Iran: incidence, serotype distribution and susceptibility to antibiotics. J Med Sci. 2008;8(6):574577. doi: 10.3923/jms.2008.574.578

48. Khan MA, Faiz A, Ashshi A. Maternal colonization of group $B$ streptococcus: prevalence, associated factors and antimicrobial resistance. Ann Saudi Med. 2015;35(6):423-427. doi: 10.5144/02564947.2015.423

49. Tazi A, Reglier-Poupet H, Dautezac F, Raymond J, Poyart C. Comparative evaluation of Strepto B ID chromogenic medium and Granada media for the detection of Group B Streptococcus from vaginal samples of pregnant women. J Microbiol Methods. 2008;73(3):263-265. doi: 10.1016/j.mimet.2008.02.024

50. Tazi A, Doloy A, Reglier-Poupet H, Hemet ME, Raymond $J$, Poyart C. Evaluation of the new chromogenic medium Strep B Select for screening of group B streptococcus in pregnant women. Pathologie Biologie. 2009;57(3):225-
228. doi: 10.1016/j.patbio.2008.09.002

51. Perry JD, Olivier M, Nicholson A, Wright J, Gould FK. Evaluation of a new chromogenic agar medium for isolation and identification of Group B streptococci. Lett Appl Microbiol. 2006;43(6):615-618 doi: 10.1111/j.1472-765X.2006.02023.x

52. Charron J, Demandion E, Laudat P. Detection rapide par culture de Streptococcus agalactiae dans les prelevements genitaux sur un nouveau milieu chromogene CHROMagar Strep B, poster 5508. Abstr. Reunion Interdisciplinaire de Chimiotherapie AntiInfectieuse, Paris. 2009.

53. Brandon M, Dowzicky MJ. Antimicrobial susceptibility among Gram-positive organisms collected from pediatric patients globally between 2004 and 2011: results from the Tigecycline Evaluation and Surveillance Trial. J Clin Microbiol. 2013;51(7):23712378. doi: $10.1128 / J C M .00157-13$

54. Adawaye C, Michel T, Paul A, Nkoa T, Hortense G, Sinata K. Vaginal colonization and resistance profile of group B Streptococcus among pregnant women in Yaounde Gynecology, Obstetric and Pediatric Hospital in Cameroon. J Clin Med Res. 2014;6:16-21. doi: 10.5897/JCMR2014.0249

55. Arif D, Urehkar AD, Kore A, Chaudhary BL, Nissar J, Singh S. Prevalence of Streptococcus agalactiae in Pregnant Women and its Antibiotic Sensitivity Pattern. Int J Curr Microbiol App Sci. 2015;4(7):315-320.

56. Mengist A, Kannan H, Abdissa A. Prevalence and antimicrobial susceptibility pattern of anorectal and vaginal group B Streptococci isolates among pregnant women in Jimma, Ethiopia. BMC Res Notes. 2016;9:351. doi: 10.1186/s13104-016-2158-4

57. Kimura K, Suzuki S, Wachino Jl, et al. First molecular characterization of group B streptococci with reduced penicillin susceptibility. Antimicrob Agents Chemother. 2008;52(8):2890-2897. doi: 10.1128/AAC.00185-08

58. Longtin J, Vermeiren C, Shahinas D, et al. Novel mutations in a patient isolate of Streptococcus agalactiae with reduced penicillin susceptibility emerging after long-term oral suppressive therapy. Antimicrob Agents Chemother. 2011;55(6):2983-2985. doi: 10.1128/AAC.01243-10

59. Banno H, Kimura K, Tanaka Y, et al. Characterization of multidrug-resistant group $B$ streptococci with reduced penicillin susceptibility forming small nonbeta-hemolytic colonies on sheep blood agar plates. J Clin Microbiol. 2014;52(6):2169-2171. doi: 10.1128/ JCM.00226-14

60. Elikwu CJ, Oduyebo O, Konig B. Antibiotic susceptibility profiles of group B streptococci (GBS) isolates from pregnant mothers in a tertiary institution in Nigeria. Int J Infect Dis. 2014;21(Suppl. 1):460. doi: 10.1016/j. ijid.2014.03.1138

61. Ji W, Zhang L, Guo Z, et al. Colonization prevalence and antibiotic susceptibility of Group B Streptococcus in pregnant women over a 6-year period in Dongguan, China. PLoS One. 2017;12(8):e0183083. doi: 10.1371/ journal.pone. 0183083

62. Gomi Y, Wang L, Matsushima H, et al. Variations in antibiotic susceptibility of group B Streptococcus in Japanese women: A long-term population-based 
cohort study. Taiwan J Obstet Gynecol. 2019;58(6):805807. doi: 10.1016/j.tjog.2019.09.014

63. Simoes JA, Aroutcheva AA, Heimler I, Faro S. Antibiotic resistance patterns of group B streptococcal clinical isolates. Infect Dis Obstet Gynecol. 2004;12(1):1-8. doi: 10.1080/10647440410001722269

64. Kitamura M, Kimura K, Ido A, et al. Relatively high rates of cefotaxime- and ceftriaxone-non-susceptible isolates among group B streptococci with reduced penicillin susceptibility (PRGBS) in Japan. J Antimicrob Chemother. 2019;74(4):931-934. doi: 10.1093/jac/ dky542

65. Mudzana R, Mavenyengwa RT, Gudza-Mugabe M. Analysis of virulence factors and antibiotic resistance genes in group $B$ streptococcus from clinical samples. BMC Infect Dis. 2021;21(1):125. doi: 10.1186/s12879021-05820-6

66. Jisuvei SC, Osoti A, Njeri MA. Prevalence, antimicrobial susceptibility patterns, serotypes and risk factors for group B streptococcus rectovaginal isolates among pregnant women at Kenyatta National Hospital, Kenya; a cross-sectional study. BMC Infect Dis. 2020;20(1):302. doi: 10.1186/s12879-020-05035-1

67. Eskandarian N, Ismail Z, Neela V, van Belkum A, Desa M, Amin NS. Antimicrobial susceptibility profiles, serotype distribution and virulence determinants among invasive, non-invasive and colonizing Streptococcus agalactiae (group B streptococcus) from Malaysian patients. Eur J Clin Microbiol Infect Dis. 2015;34(3):579584. doi: 10.1007/s10096-014-2265-x

68. Ghanbarzadeh N, Mehramiz M, Gannadkafi M, Namaei MH. The prevalence of group B Streptococcus rectovaginal colonization and antimicrobial susceptibility pattern among pregnant women: A descriptive-analytical study. Modern Care J. 2017;14(3):e66391. doi: 10.5812/modernc.66391

69. Dmitriev A, Suvorov A, Shen AD, Yang YH. Clinical diagnosis of group $B$ streptococci by $s c p B$ gene based PCR. Indian J Med Res. 2004;119:233-236.

70. Dutra V, Alves V, Olendzki A, et al. Streptococcus agalactiae in Brazil: serotype distribution, virulence determinants and antimicrobial susceptibility. BMC Infect Dis. 2014;14:323. doi: 10.1186/1471-2334-14323

71. Bobadilla F, Novosak M, Cortese I, Delgado O, Laczeski $M$. Prevalence, serotypes and virulence genes of Streptococcus agalactiae isolated from pregnant women with 35-37 weeks of gestation. BMC Infectious Diseases. 2021;21:73. doi: 10.1186/s12879-02005603-5 